\title{
Josué de Castro e a Geografia da Fome no Brasil
}

\author{
Josué de Castro and The Geography of Hunger in Brazil
}

\footnotetext{
${ }^{1}$ Centro de Ciências da Saúde, Universidade

Federal de Santa Catarina Florianópolis, Brasil.

Correspondência F. A. G. Vasconcelos Departamento de Nutrição, Centro de Ciências da Saúde Universidade Federal de Santa Catarina.

Campus Universitário

Trindade, Florianópolis, SC 88040-970, Brasil.

fguedes@floripa.com.br
}

\section{Abstract}

The aim of this article is to reinterpret the classic work Geografia da Fome [The Geography of Hunger], first published in 1946. The article provides a summary of the five food area maps and the main nutritional deficiencies in Brazil, based on Josué de Castro's original conception. Current$l y$, the nutritional epidemiological profile identified by Josué de Castro, characterized by nutritional deficiencies (malnutrition, vitamin deficiencies, endemic goiter, iron deficiency anemia, etc.), overlap with chronic non-communicable diseases (obesity, diabetes, dyslipidemias, etc.). However, the complex and paradoxical issue of hunger is a persistently recurrent theme in Brazil. Given a series of current dilemmas, including the planet's ecological sustainability and the need to guarantee the human right to adequate, healthy nutrition, it is urgent to reawaken the struggle led by Josué de Castro for the adoption of a sustainable economic development model and a society free of poverty and hunger.

Hunger; Feeding Behavior; Nutritional Surveillance
Francisco de Assis Guedes de Vasconcelos 1

\section{Introdução}

Josué de Castro nasceu em 5 de setembro de 1908, em Recife, Pernambuco, Brasil. Filho de um agricultor do Sertão Nordestino que em 1877, em função da seca, migrou para a capital, viveu sua infância e adolescência em um bairro pobre, às margens do rio Capibaribe 1,2,3. Em 1929, após concluir o Curso de Medicina da Universidade do Brasil, retornou ao Recife para dar início a uma consagrada trajetória político-intelectual, dedicada, particularmente, à complexa e paradoxal problemática da fome e suas formas de enfrentamento ${ }^{4}$. A sua vastíssima produção intelectual, de abrangência internacional, composta por mais de 200 títulos, tem sido objeto de estudo de distintas investigações 3,4,5,6,7,8,9.

O objetivo geral do presente artigo é realizar uma releitura do clássico Geografia da Fome, publicado pela primeira vez em 1946 10. Como objetivos específicos, em um primeiro momento, realiza-se uma síntese do mapa das cinco áreas alimentares do Brasil traçado em Geografia da Fome, procurando identificar as principais características dos seus regimes alimentares. Em um segundo momento, realiza-se uma síntese do mapa das principais carências nutricionais existentes no Brasil, de acordo com o delineamento de Josué de Castro 10.

Em Geografia da Fome, Josué de Castro introduz os conceitos de áreas alimentares, áreas de fome endêmica, áreas de fome epidêmica, 
áreas de subnutrição, mosaico alimentar brasileiro e, por conseqüência, traça o primeiro mapa da fome no país. Por áreas alimentares, concebe uma determinada região geográfica que dispõe de recursos típicos, dieta habitual baseada em determinados produtos regionais e com seus habitantes refletindo, em suas características biológicas e sócio-culturais, a influência marcante da dieta. Por área de fome endêmica, concebe uma determinada área geográfica em que pelo menos metade da população apresenta nítidas manifestações de carências nutricionais permanentes. Por áreas de fome epidêmica, concebe uma determinada área geográfica em que pelo menos metade da população apresenta nítidas manifestações nutricionais transitórias. Por áreas de subnutrição, concebe uma determinada área geográfica em que os desequilíbrios e as carências alimentares, sejam em suas formas discretas ou manifestas, atingem grupos reduzidos da população. E por mosaico alimentar brasileiro, concebe a diferenciação regional dos tipos de dieta existentes no país, oriundas das variadas categorias de recursos naturais (alimentos) e das distintas etnias que constituíram a nação brasileira ${ }^{9}$.

De acordo com Castro 10, o método de investigação que norteou a elaboração da Geografia da Fome foi baseado nos princípios estabelecidos pelos geógrafos alemães Carl Ritter (1779-1859) e Alexander von Humboldt (1769-1859), pelo geógrafo francês PaulVidal de La Blache (1845-1918), entre outros. Para seu autor, o objetivo básico da Geografia da Fome consiste em "localizar com precisão, delimitar e correlacionar os fenômenos naturais e culturais que ocorrem à superfície da terra" 10 (pp. 34-5). Assim sendo, afirma que o propósito do seu estudo foi realizar uma sondagem de natureza ecológica sobre o fenômeno da fome no Brasil, orientado pelos princípios geográficos da localização, extensão, causalidade, correlação e unidade terrestre 10 .

Por outro lado, ao introduzir o uso dos termos fome endêmica e fome epidêmica, em nota explicativa, Castro faz alusão à adoção do conceito de epidemiologia da fome, explicitando a influência que sofreu do conceito de epidemiologia admitido por Wade Hampton Frost (1880-1938) e do conceito de epidemiologia do diabetes e do câncer defendido por Wilson George Smillie (18861971). Sendo assim, embora explicitando sua maior identificação com o método geográfico, os aspectos biológicos, médicos e higiênicos do fenômeno da fome também são enfocados em seu ensaio ecológico.

\section{O mapa das áreas alimentares do Brasil}

A partir de Geografia da Fome, o país seria dividido em cinco diferentes áreas alimentares assim distribuídas: (1) Área Amazônica - à época, abrangia os estados do Amazonas e Pará, parte dos estados do Mato Grosso, Goiás e Maranhão e os territórios do Amapá e Rio Branco; (2) Nordeste Açucareiro ou Zona da Mata Nordestina - à época, correspondia a todo o litoral nordestino, do Estado da Bahia ao Ceará, compreendendo uma faixa territorial com largura média de $80 \mathrm{~km}$; (3) Sertão Nordestino - correspondendo, à época, às terras centrais dos estados do Piauí, Ceará, Rio Grande do Norte, Paraíba, Pernambuco, Alagoas, Sergipe e Bahia; (4) Centro-Oeste - compreendia os estados de Minas Gerais, Goiás e Mato Grasso; e (5) Extremo Sul - que à época abrangia os estados da Guanabara, Rio de Janeiro, São Paulo, Paraná, Santa Catarina e Rio Grande do Sul.

\section{O regime alimentar da Área Amazônica}

De acordo com o mapa das áreas alimentares do Brasil (Figura 1), a Área Amazônica apresentava como dieta básica o consumo de farinha de mandioca, associada ao feijão, peixe e rapadura. Em relação aos fatores etno-culturais que influenciavam a constituição da dieta, Castro 10 aponta a predominância da cultura indígena sobre as culturas dos brancos portugueses e negros africanos. O alimento básico da dieta, a farinha de mandioca, era consumido em diferentes preparações sob a forma de farofas, mingaus, beijus e bebidas fermentadas, sendo misturado a outros alimentos, oriundos da flora silvestre (frutos, sementes e ervas), da fauna aquática e terrestre (peixes, crustáceos, tartarugas, tracajás, jabutis, antas, macacos e patos), além da incipiente agricultura regional. Destaca o largo consumo de pimentas e outras ervas na preparação dos pratos regionais como uma importante contribuição da cultura indígena. Em relação aos frutos regionais, é interessante notar que, já àquela época, ele apontava algumas importantes características nutricionais do buriti e açaí (ricos em betacaroteno ou vitamina A) e castanha-do-pará (proteínas completas e ácidos graxos). A conclusão do autor sobre a dieta amazônica foi que se tratava de uma alimentação pouco trabalhada e atraente e que sua análise biológica e química revelava inúmeras deficiências nutritivas 10. 
Figura 1

Mapa das áreas alimentares do Brasil.

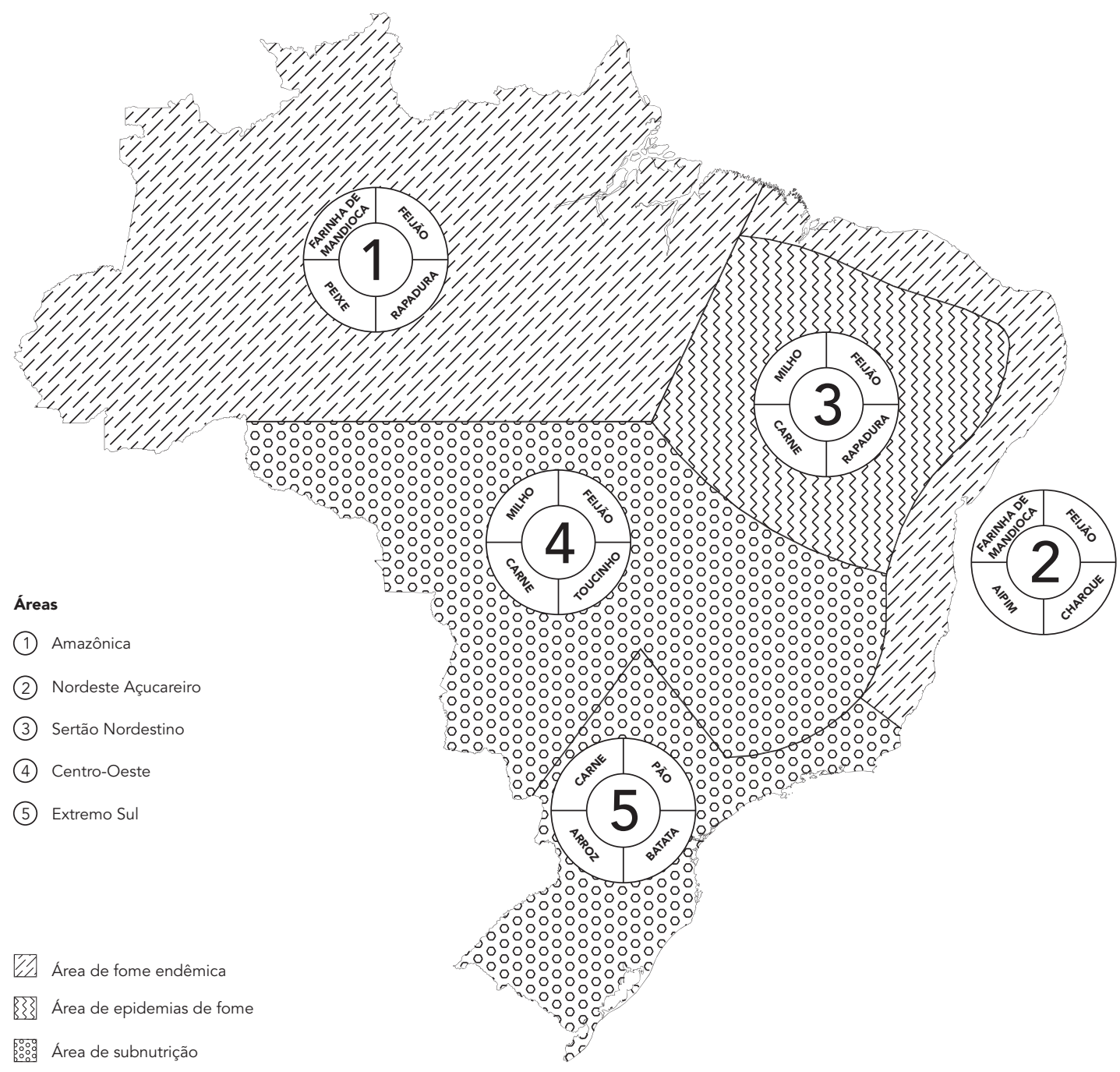

\section{O regime alimentar do Nordeste Açucareiro}

No Nordeste Açucareiro a dieta básica era o consumo de farinha de mandioca, associada ao feijão, aipim e charque (Figura 1). De acordo com Castro 10 , esse regime alimentar era produto da inter-relação das culturas alimentares dos indígenas da região, dos colonizadores portugueses e dos negros africanos, tendo a cultura alimentar do negro africano uma influência mais expressiva e valorizadora sobre os hábitos alimentares do que as demais.

Ele aponta a existência de distintas subáreas alimentares nessa região nordestina. Inicialmen- te, faz distinção entre duas subáreas alimentares: a litorânea e a da mata ou da cana-de-açúcar. Ao longo da sua abordagem aparece referência a uma subárea alimentar do sururu no Estado de Alagoas e à especificidade da cozinha baiana. Ao final, também descreve a área alimentar do cacau que, à época, se estendia do Recôncavo para o sul da Bahia até o Espírito Santo 10.

Na descrição da área litorânea destaca a riqueza de proteínas e sais minerais, oriundos dos alimentos marinhos (peixes, moluscos e crustáceos) e a participação de dois produtos vegetais de alto valor nutritivo: o coco e o caju. O coco contribuía com o aporte de gordura, proteínas e 
sais minerais da dieta, participando de uma infinidade de preparações típicas: feijão de coco, peixe de coco, arroz de coco, vatapá, canjica, pamonha, mungunzá, doce de coco, cocada, entre outras. O caju, por sua vez, era rico em vitaminas (em ácido ascórbico) e em proteínas de alto valor biológico contidas na castanha 10 .

Vale destacar a análise apresentada sobre os tabus alimentares da região, sobretudo em relação ao consumo de frutas como manga, jaca, abacaxi, melancia, abacate, laranja, entre outras. Para Castro 10, o grande número de superstições e restrições ao consumo de certos alimentos, sem nenhum fundamento biológico, decorria da sobrevivência cultural das interdições alimentares impostas por questões econômicas pelos senhores de engenho a seus escravos e moradores. Nesse aspecto, vale lembrar que grande parte dos tabus alimentares identificados continua sua reprodução no imaginário alimentar da população brasileira 11,12,13.

\section{O regime alimentar do Sertão Nordestino}

O Sertão Nordestino tinha como dieta básica o consumo de milho, associado ao feijão, carne (gado, carneiro e cabra) e rapadura (Figura 1). De acordo com Castro 10, esse regime alimentar tinha predominância da influência cultural colonial (árabe-portuguesa), sendo o mais isento das influências das culturas dos índios e negros.

O milho foi considerado o alimento básico da dieta, sendo consumido quase que pela totalidade da população em quantidades consideradas elevadas. Constituía a base calórica da dieta, sendo usado no preparo de vários pratos típicos: cuscuz, angu, pamonha e canjica. Segundo Castro 10 , seu consumo associado ao do leite resultava numa combinação nutricional muito feliz, uma vez que a proteína caseína do leite completava as deficiências em aminoácidos da proteína zeína do milho.

O leite e seus derivados como coalhada fresca ou escorrida, queijo e manteiga eram consumidos em abundância, constituindo alimentos integrantes da dieta do sertanejo nordestino. Para completar o aporte de proteínas de origem animal, observava-se o consumo habitual de carne (boi, carneiro e cabra) em distintas preparações: carne com abóbora e leite; carne-de-sol; charque; paçoca, buchada, panelada etc. 10 .

Completava o regime habitual do sertanejo nordestino o consumo de feijão (principalmente do tipo macassar), farinha de mandioca, batatadoce, inhame, rapadura e café. O consumo habitual de frutas e verduras era muito limitado, constituindo falha visível da alimentação do sertanejo. Sendo assim, ele identificava a ingestão limitada de frutas regionais como umbu, piqui, quibá, cajarana e quixaba. Identificava também o consumo limitado de verduras como abóbora, maxixe, e cebolinha e coentro, usados como temperos.

Castro 10 concluiu que o regime alimentar habitual da área do Sertão Nordestino apresentavase quantitativa e qualitativamente equilibrado, atendendo sem déficits e sem excessos às necessidades nutricionais do sertanejo: "É esta mesma parcimônia calórica, sem margens a luxo, que faz do sertanejo um tipo magro e anguloso, de carnes enxutas, sem arredondamentos de tecidos adiposos e sem nenhuma predisposição ao artritismo, à obesidade e ao diabetes, doenças essas provocadas, muitas vezes, por excesso alimentar" 10 (p. 207).

Entretanto, esse equilíbrio nutricional estava sujeito às rupturas cíclicas dos períodos de seca, quando se desorganizava completamente a economia regional e instalava-se a fome epidêmica. Nesse sentido, Castro 10 relata que nos períodos de seca o sertanejo passava imediatamente para um regime de subalimentação, limitando a quantidade e a variedade de alimentos, reduzindo a sua dieta ao consumo de um pouco de milho, feijão e farinha de mandioca. Quando a seca persistia e esses recursos alimentares se esgotavam, o sertanejo lançava mão de outras estratégias de sobrevivência, passando a consumir as "iguarias bárbaras" do sertão: raízes, sementes, frutos e animais resistentes à seca. Entre as "iguarias bárbaras" ele destaca: farinha de macambira, xique-xique, pereira brava, macaúba e mucunã, palmito de carnaúba, raízes de umbuzeiro, pau-pedra, serrote e maniçoba, sementes de fava-brava, manjerioba, beijus de catolé, gravatá e macambira.

Em relação ao consumo desses alimentos exóticos Castro 10 (p. 220-1) conclui: "Quando o sertanejo lança mão destes alimentos exóticos é que o martírio da seca já vai longe e que sua miséria já atingiu os limites de sua resistência orgânica. É a última etapa de sua permanência na terra desolada, antes de se fazer retirante e descer aos magotes, em busca de outras terras menos castigadas pela inclemência do clima".

\section{O regime alimentar do Centro-Oeste}

No Centro-Oeste a dieta básica era o consumo de milho, associado ao feijão, carne e toucinho (Figura 1). O prato típico foi identificado como o "tutu de feijão mineiro", preparado à base de farinha de milho, feijão, gordura, toucinho e lombo de porco. Esse foi considerado por Castro como de "alto valor calórico", mas qualitativamente de valor nutritivo inferior ao do "angu ou do cuscuz de milho com leite” da área do Sertão Nor- 
destino, principalmente por seu teor mais baixo em cálcio e vitaminas. Entretanto, salienta que a dieta básica da região ganhava valor biológico a partir do consumo associado de vegetais verdes, principalmente couve mineira, outras hortaliças e frutas, principalmente laranja, mamão, banana e abacate. Com base na análise química do regime alimentar, afirma que não havia deficiência calórica na região, pelo contrário, deveria haver excesso calórico. Concluiu sua análise de forma um tanto preconceituosa ao afirmar que esse padrão alimentar resultava em "maior incidência da obesidade e do diabete, e na formação do tipo biológico dos mineiros lentos e pesados, conservadores e pachorrentos" 10 (p. 267).

\section{O regime alimentar do Extremo Sul}

O Extremo Sul consumia basicamente o arroz, pão, batata e carne (Figura 1). À época, por constituir a área mais rica e de maior desenvolvimento, tanto agrícola como industrial, também foi considerada a região de maior variedade alimentar, de mais alto consumo de verduras e frutas e, portanto, de mais elevado padrão alimentar. Além dos fatores econômicos e geográficos (clima, solo, pluviosidade etc.), Castro 10 ressalta os determinantes etno-culturais que possibilitavam diversificação e melhoria do padrão alimentar da região. Assim, as distintas etnias que migraram para a região, compostas por italianos, japoneses, alemães, poloneses, lituanos, entre outros, em muito contribuíram para a constituição do seu diversificado mosaico alimentar. Ele destaca a presença de distintas subáreas alimentares nessa região: (1) Subárea de influência italiana, caracterizada pelo largo consumo de trigo sob a forma de macarrão, ravioli e spaghetti; (2) Subárea localizada no Rio Grande do Sul, caracterizada pelo complexo alimentar do churrasco e do mate-chimarrão; (3) Subárea de influência japonesa, localizada em torno da capital de São Paulo e outros centros urbanos, caracterizada por abundante consumo de verduras; e (4) Subárea de influência germânica, caracterizada por um consumo mais freqüente de aveia, centeio, lentilhas, hortaliças, frutas, carne de porco (salsichas, bacon, presunto, defumados), pão preto, chucrute e cerveja.

\section{O mapa das carências nutricionais do Brasil}

\section{As carências nutricionais da Amazônia}

A Região Amazônica, considerada uma das áreas de fome endêmica, caracterizava-se pela presen- ça de deficiências protéicas, vitamínicas e de sais minerais (Figura 2). À época, as carências nutricionais endêmicas eram: carências protéicas, de vitamina B2 (arriboflavinose); de ferro (anemias) e de cloreto de sódio. As formas frustas ou subclínicas eram: carências protéicas; de vitaminas A, B1 e niacina (pelagra) e de cálcio (sem manifestação de raquitismo). A carência de vitamina B1 (beribéri) aparecia em forma típica epidêmica. Em relação ao beribéri, vale ressaltar que ele destaca o período de 1870 a 1910, conhecido como ciclo econômico da borracha amazônica, como uma fase epidêmica desta carência nutricional na região. Ressalta-se ainda a interessante análise que ele faz sobre a associação entre a insuficiência alimentar quantitativa, caracterizada por um baixo consumo calórico, a adaptação orgânica forçada a partir desta situação permanente e a apregoada preguiça dos povos dessa região equatorial. Para Castro 10 (p. 76), “a preguiça dos povos equatoriais é um meio de defesa ou sobrevivência, funcionando como um sinal de alarme numa caldeira que diminui a intensidade de suas combustões, quando lhe falta o combustivel".

\section{As carências nutricionais do \\ Nordeste Açucareiro}

O Nordeste Açucareiro, considerado uma área de fome endêmica, apresentava como manifestações diretas da deficiência do regime alimentar: carências calóricas, protéicas, de vitaminas e minerais. As formas endêmicas das carências nutricionais identificadas foram: carências protéicas, de vitaminas A, B1 e B2 e dos minerais ferro e cloreto de sódio. As manifestações subclínicas identificadas foram: carências protéicas; de vitaminas B1, C (escorbuto) e niacina e do mineral cálcio (Figura 2) 10.

Castro destaca que em conseqüência da deficiência calórica da dieta, decorria a reduzida capacidade de trabalho do nordestino da Zona da Mata, em relação aos trabalhadores mais bem alimentados de outras regiões do país. Chama a atenção para uma possível associação entre a deficiência permanente de proteínas da dieta e os índices de baixa estatura dos habitantes do brejo nordestino, os trabalhadores dos engenhos e usinas de açúcar. Como confronto, também chama a atenção para uma possível associação entre a dieta rica em proteínas e sais minerais e os índices de estatura elevada dos habitantes do litoral, as populações costeiras de pescadores.

Ao descrever o mapa das carências de vitaminas A, B1, B2, C e niacina, relativiza a magnitude e a gravidade do quadro, ressaltando que estas carências não eram tão abundantes como deveria se esperar. Como exceção, destaca a carência 
Mapa das principais carências nutricionais existentes nas diferentes áreas alimentares do Brasil.

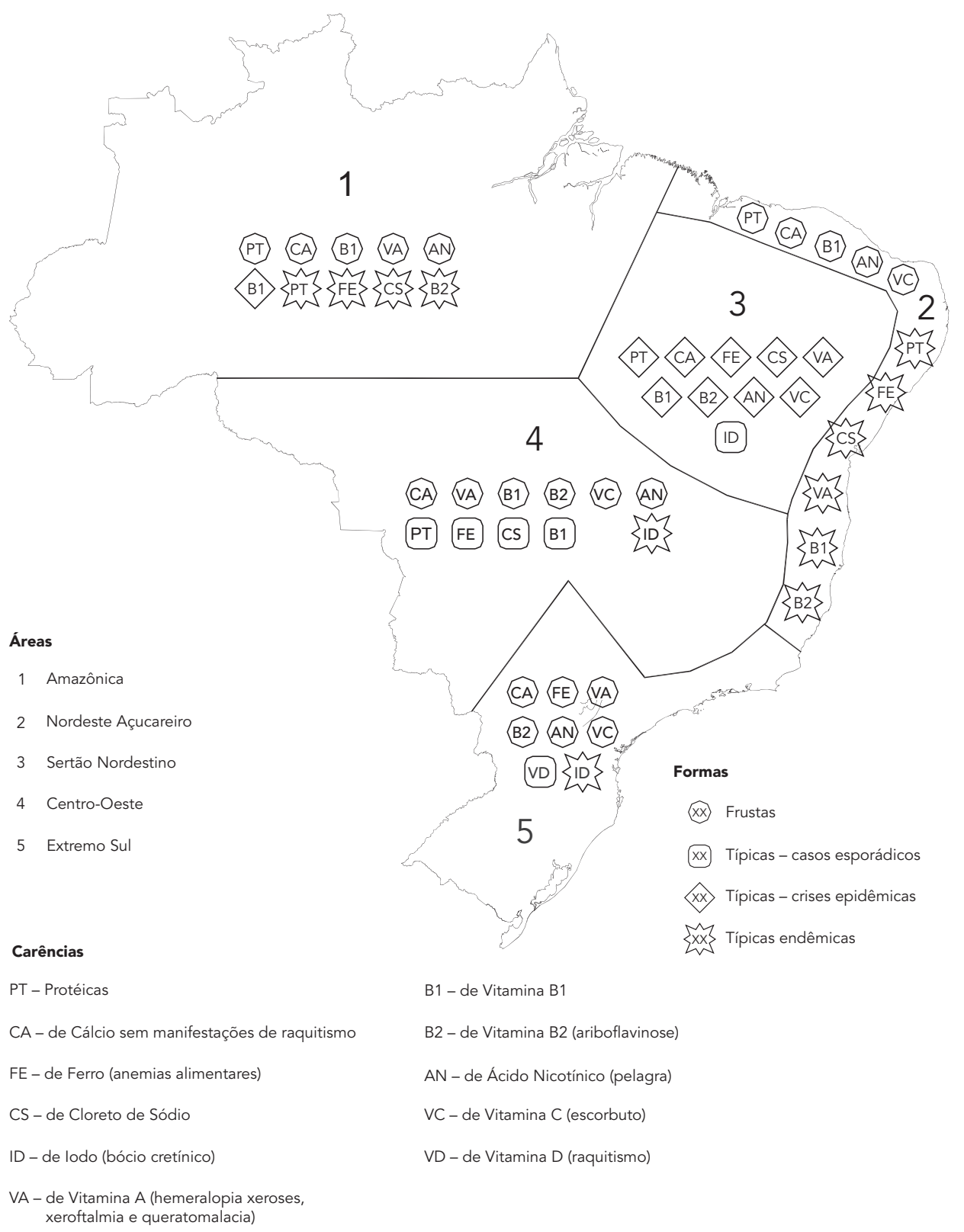

de vitamina B2 (arriboflavinose), afirmando ser esta abundante e generalizada entre crianças pobres das áreas rurais e urbanas da região. É interessante notar que ele aponta como explicação a possível influência de fatores protetores ou preventivos presentes na dieta regional, tais como condimentos e ingredientes especiais usados, sobretudo na cozinha baiana: o azeite-de-dendê (fonte de beta-caroteno ou provitamina A) e as variadas espécies de pimenta (fontes de ácido ascórbico) 10.

Em relação às carências minerais, aponta a deficiência de ferro (anemia alimentar) como a manifestação endêmica mais generalizada, a qual seria responsável pelo estereótipo de palidez, apatia e depressão física do habitante do brejo - o Jeca-Tatu Nordestino. Entretanto, apenas um estudo sobre a prevalência de anemia ferropriva 
é referido, segundo o qual $40 \%$ dos escolares da cidade de Salvador (Bahia) apresentavam baixas taxas de hemoglobina 10.

Ressalta-se ainda a importante análise realizada a respeito das conseqüências do consumo alimentar excessivo ou desequilibrado verificado entre os habitantes mais abastados, os senhores de engenhos e suas famílias. De acordo com Castro 10, a dieta com excesso de carboidratos, sobretudo, com excesso de açúcar e falta de frutas, apresentava como conseqüência a grande incidência de diabetes e avitaminoses $\mathrm{B}$ em certas famílias de senhores de engenhos. Nesse aspecto, faz uso de uma brilhante metáfora: “ $O$ açúcar em excesso de sua dieta desequilibrando as trocas metabólicas, como a cana desequilibrou de maneira tão nociva o metabolismo econômico da região. É como se a terra se vingasse do homem, fazendo-o sofrer de uma doença semelhante à sua - o organismo todo saturado de açúcar" 10 (pp. 155-6).

\section{As carências nutricionais do} Sertão Nordestino

De acordo com Castro 10, a área do Sertão do Nordeste caracterizava-se pela atuação de um tipo de fome diferente, aquela que se apresentava em surtos epidêmicos ou agudos nos períodos de seca ou estiagem. Eram epidemias de fome global quantitativa e qualitativa que afetavam de forma bastante violenta e sem discriminação todos os habitantes da região. Apresentava como formas endêmicas: carências protéicas, de vitaminas A, B1, B2, C e niacina e dos minerais cálcio, ferro e cloreto de sódio. A carência de iodo (bócio) apresentava-se em sua forma subclínica (Figura 2).

\section{As carências nutricionais do Centro-Oeste}

A área do Centro-Oeste foi considerada como uma "área de subnutrição, de desequilíbrio e de carências parciais, restritas a determinados grupos ou classes sociais" 10 (p. 265). A única forma endêmica descrita foi a carência de iodo (bócio endêmico). As carências de proteínas, de vitamina B1, de ferro e de cloreto de sódio foram identificadas como formas típicas esporádicas. As carências de vitaminas A, B1, B2, C e niacina e de cálcio foram identificadas em suas formas frustas (Figura 2) 10.

Em relação ao bócio endêmico, relata que esta deficiência nutricional grassava no país desde os tempos coloniais, apresentando maior incidência nos estados de Minas Gerais, São Paulo, Rio de Janeiro, Paraná, Goiás e Mato Grosso. De acordo com Castro 10, à época, estudos realizados com escolares de Minas Gerais e São Paulo verificaram incidências de $44 \%$ e $60 \%$ de bócio endêmico, respectivamente.

\section{As carências nutricionais do Extremo Sul}

O Extremo Sul também foi considerado uma área de deficiências alimentares discretas e menos generalizadas, apresentando "carências parciais, restritas a determinados grupos ou classes sociais" 10 (p. 265) Era a região que tinha o melhor perfil epidemiológico nutricional. As carências de vitaminas A, B2, C e niacina, de cálcio e de ferro apareciam em suas formas subclínicas. A carência de vitamina D (raquitismo) aparecia sob forma típica esporádica. A carência de iodo manifestava-se de forma endêmica (Figura 2). Entretanto, ao concluir sua análise ele faz um alerta sobre o aumento da incidência da carência de proteínas, que se manifestava em quadros típicos de kwashiorkor, entre crianças das classes pobres e proletárias dos grandes centros urbanos da região, principalmente Rio de Janeiro e São Paulo 10.

\section{Considerações finais}

A releitura de Geografia da Fome evidencia quão viva, polêmica e sedutora permanece esta obra sexagenária. Nos dias atuais, ao perfil epidemiológico nutricional traçado por Josué de Castro, caracterizado pelas carências nutricionais (desnutrição, hipovitaminoses, bócio endêmico, anemia ferropriva etc.), sobrepuseram-se as doenças crônicas não-transmissíveis (obesidade, diabetes, dislipidemias etc.). Nesse aspecto, tanto o mapa das cinco áreas alimentares como o das principais carências nutricionais existentes no Brasil traçados em Geografia da Fome precisam ser redesenhados em função deste novo perfil epidemiológico nutricional brasileiro. Tarefa imprescindível, mas que ainda está por vir. A questão da complexa e paradoxal problemática da fome, entretanto, permanece como uma temática recorrente no Brasil. Portanto, diante de alguns dilemas da atualidade, tais como aqueles que dizem respeito à sustentabilidade ecológica do planeta e à garantia do direito humano à alimentação, torna-se imperante reacender a luta defendida por Josué de Castro pela adoção de um modelo de desenvolvimento econômico sustentável e uma sociedade sem miséria e sem fome. 


\section{Resumo}

O objetivo deste artigo é realizar uma releitura do clássico Geografia da Fome, publicado pela primeira vez em 1946. Realiza-se uma síntese dos mapas das cinco áreas alimentares e das principais carências nutricionais existentes no Brasil, de acordo com o delineamento realizado por Josué de Castro. Nos dias atuais, ao perfil epidemiológico nutricional desenhado por Josué de Castro, caracterizado pelas carências nutricionais (desnutrição, hipovitaminoses, bócio endêmico, anemia ferropriva etc.), sobrepuseram-se as doenças crônicas não-transmissiveis (obesidade, diabetes, dislipidemias etc.). Entretanto, a questão da complexa e paradoxal problemática da fome permanece como uma temática recorrente no Brasil. Diante de alguns dilemas da atualidade, tais como aqueles que dizem respeito à sustentabilidade ecológica do planeta e à garantia do direito humano à alimentação, torna-se imperante reacender a luta defendida por Josué de Castro pela adoção de um modelo de desenvolvimento econômico sustentável e uma sociedade sem miséria e sem fome.

Fome; Comportamento Alimentar; Vigilância Nutricional

\section{Referências}

1. Linhares MYL. Biografia. In: Castro J. Geografia da fome (o dilema brasileiro: pão ou aço). 10a Ed. Rio de Janeiro: Antares Achiamé; 1980. p. 333-7.

2. L'Abbate S. As políticas de alimentação e nutrição no Brasil. I. Período de 1940 a 1964. Rev Nutr 1988; 1:87-138.

3. Magalhães R. Fome: uma (re)leitura de Josué de Castro. Rio de Janeiro: Editora Fiocruz; 1997.

4. Vasconcelos FAG. Fome, eugenia e constituição do campo da nutrição em saúde pública em Pernambuco: uma análise de Gilberto Freyre, Josué de Castro e Nelson Chaves. Hist Ciênc Saúde-Manguinhos 2001; 8:315-39.

5. Arruda BKG. Geografia da Fome: da lógica regional à universalidade. Cad Saúde Pública 1997; 13: 545-9.

6. Vasconcelos FAG. Os Arquivos Brasileiros de Nutrição: uma revisão sobre produção científica em nutrição no Brasil (1944 a 1968). Cad Saúde Pública 1999; 15:303-16.

7. Lima ES. Mal de fome e não de raça: gênese, constituição e ação política da educação alimentar Brasil - 1934-1946. Rio de Janeiro: Editora Fiocruz; 2000.

8. Melo Filho DA. Mangue, homens e caranguejos em Josué de Castro: significados e ressonâncias. Hist Ciênc Saúde-Manguinhos 2003; 10:505-24.

9. Vasconcelos FAG. Tendências históricas dos estudos dietéticos no Brasil. Hist Ciênc Saúde-Manguinhos 2007; 14:197-219.

10. Castro J. Geografia da fome (o dilema brasileiro: pão ou aço). 10a Ed. Rio de Janeiro: Antares Achiamé; 1980.

11. Trigo M, Roncada MJ, Stewien GTM, Pereira IMTB. Tabus alimentares em Região do Norte do Brasil. Rev Saúde Pública 1989; 23:455-64.

12. Ramalho RA, Saunders C. O papel da educação nutricional no combate às carências nutricionais. Rev Nutr 2000; 13:11-6.

13. Costa-Neto EM. Restrições e preferências alimentares em comunidades de pescadores do Município de Conde, Estado da Bahia, Brasil. Rev Nutr 2000; 13:117-26.

Recebido em 04/Jul/2008

Versão final reapresentada em 27/Ago/2008

Aprovado em 04/Set/2008 